\title{
Studying Dictionary Use Among the Law Graduates in Pakistan:
}

\section{A Lexicographic Inquiry}

\author{
Mamona Yasmin Khan ${ }^{1}$ \& Masroor Sibtain ${ }^{2}$ \\ 1 Department of English, The Women University, Multan, Pakistan \\ ${ }^{2}$ Government College of Science, Bosan Road, Multan, Pakistan \\ Correspondence: Mamona Yasmin Khan, Department of English, The Women University, Multan, Pakistan. \\ E-mail: mamonakhan1234@gmail.com
}

\author{
Received: January 2, 2019 Accepted: February 22, 2019 Online Published: March 7, 2019 \\ doi:10.5539/ijel.v9n2p429 URL: https://doi.org/10.5539/ijel.v9n2p429
}

\begin{abstract}
Specialized Lexicography as it stands today owes much to the user's centred approach while dictionary making. The present study empirically investigates the use of law dictionaries by the law graduates in Pakistan. The study has taken account of dictionary usage among the Pakistani law graduates within the framework of Function Theory of Lexicography. The study being descriptive qualitative research is placed within pragmatic paradigm. A sample of six hundred law students, who were non-native learners of English and learning this language in ESP context, was drawn and responses were recorded through data tools i.e., questionnaire, semi-structured protocols and observation as favoured in other studies of the similar nature mostly outside Pakistan. Data were analysed through SPSS and presented in tables and graphs. The analysis of qualitative data, however, is based on thematic approach. The study revealed that that existing law dictionaries do not cater to the decoding as well as encoding language needs of the learners although they were found more in need to consult lexicographical resources in law studies because of the complex nature of legal discourse. The study also revealed that the law graduates sadly lacked in awareness regarding both the right choice of law dictionaries best suited to address their potential needs and skills to exploit the dictionary (ies) in order to retrieve the required information successfully. They preferred to use monolingual, bilingual law dictionaries, general purpose dictionaries (hard copy and digital) along with the online resources as a good combination to solve their language problems. Moreover, their reference skills were found weak which may be improved through explicit instructions on dictionary use. The study is part of a doctoral research.
\end{abstract}

Keywords: specialized lexicography, function theory, Pakistani law graduates, protocols, law dictionaries, reference skills

\section{Introduction}

Communicative competence of foreign language learners can be gauged from their good command of vocabulary in the target language which surely is a challenging and time-consuming task. Learning English as a foreign language (EFL context) without any sociolinguistic, psycholinguistic and pedagogical variables is considered a very difficult issue at all levels in Pakistan but when it comes to English for Specific Purposes (ESP context) like legal education, the issue becomes more challenging, requiring learners' best level of proficiency at syntactic, semantic, pragmatic and stylistic level to use the language independently and confidently. Therefore, the role of a dictionary that addresses the potential language needs of learners at an optimal level assumes greater significance. Nielsen (2015) argues that dictionaries, providing help in cognitive and communication situations are important information tools in today's society, especially when two different languages and legal systems are involved.

Dictionary consultation, no doubt, is a complex process which involves skills and good knowledge of how to exploit the dictionary for retrieving the specific information successfully and the law students are no exception to it as they need to bridge the gap between their L1 and L2 and develop their competence in acquiring vocabulary both in specialized as well as general language for successful communication in professional settings. Tarp (2009) argues that research on the use of the dictionary, in order to be useful, should investigate i) user types, ii) types of use situation, iii) types of user's needs, iv) dictionary use by the users and v) user's satisfaction. He further states that research on actual dictionary use can lead to reliable information as publishers rely on 
empirical data collected from the target users for compiling dictionaries.

\section{Literature Review}

\subsection{Theoretical Framework}

A user-friendly lexicographical tool can only be successful if it is guided by some sound lexicographical theory as stated by Nikuze (2014) and that theoretical representation of data in a user-friendly dictionary can only be achieved when the underlying model is informed by sound and reliable lexicographic theories that make provision for the central role of the user in dictionary compilation. In the present investigation, such a theoretical basis is found in the theory of lexicographic functions which, according to Fuertes-Olivera and Tarp (2011), was developed by researchers at the Aarhus School of Business and Social Sciences, headed by Henning Bergenholtz, Sven Tarp and Sandro Nielsen. The goal was to establish the theoretical understanding and to optimize the theoretical potential of the user's perspective in the general theory of lexicography by developing the concept of lexicography theory. Function theory of lexicography considers dictionaries as tools made for the purpose of fulfilling specific user needs (Bergenholtz \& Nielsen, 2006, p. 283).

Tarp (2009) states that the recent decades have witnessed a parallel development in theoretical lexicography as well as in the phenomenon relevant to acquiring more knowledge about the usage of lexicographic practical products such as dictionaries. This increased interest is ascribed to a historic conference on Lexicography held in USA in 1960, where one of the conclusions, as stated by Householder (1967), was that "dictionaries should be designed with a particular set of users in mind and for their specific needs." At this starting point it is understandable that a growing number of lexicographers focused on their users and needs and began organizing research projects in this field although the development was slow.

\subsection{An Overview of Relevant Studies in the Field}

Over the past two decades, specialized lexicography has created a large and growing amount of practical products. The number of published specialized reference works has increased significantly on the one hand while on the other hand, the lexicographic quality of most of these works is inadequate. Several factors might have contributed to this situation and the lack of sufficient theoretical framework factor is one of them. He (ibid) further argues that research on actual dictionary use can lead to reliable information about this type of situation whereas it can provide suppositions and vague ideas about the problems and needs of the users that appear in its preceding extra-lexicographic user situation. In this respect, he further states that it is important to conduct useful research on the use of the dictionary, it should not only produce knowledge on how to use the dictionaries, but also on who the users are, when, where, why and how they use dictionaries and with results. The same applies to the dictionary usage where knowing the user needs as well as user's general experience is necessary so that relevant conclusions can be drawn. Similarly, it makes no sense to talk about user needs if these needs are dealt with in an abstract way without linking them to specific types of users and situations.

According to Tarp (2009), the 1980s and 1990s were marked by the publication of an increasing number of articles on user research, mainly as individual contributions to books periodically. Since the late 1990s, numerous monographs, books and themes dedicated exclusively to this subject have been added, such as Atkins (1998), which includes a collection of contributions from various researchers such as Nesi (2000), Tono (2001), Wingate (2002), Thumb (2004), Lew (2004) and Dziemianko (2006), which are all in the form of monographs.

McCreary and Dolezal (1998) stated that systematic research on the use of the dictionary includes observation of dictionary consultation and interaction between the dictionary user and the dictionary has a relatively short tradition and some scholars have criticized its academic quality but empirical dictionary research has gained importance steadily in the last decade. There is a rapid growth of literature on the actual use of the dictionary, which shows that this field of research on the use of a dictionary wise popularity gradually as Hartman (2000) emphasized on the need for more empirical studies on dictionary use growing unprecedentedly.

Apart from the studies conducted by Ard (1982), Descamps and Vaunaize (1983), Mitchell (1983), Hatherall (1984), Tono (1984), Neubauer (1985), Wiegand (1985), Krings (1986), Iqbal (1987), Miller and Gildea (1987), Tomaszczyk (1987), Neubach and Cohen (1988), Tono (1988), Atkins and Knowles (1990) and others where these researchers wanted to find out the ways and proficiency dictionaries were consulted.

The researcher will present a humble overview of the related literature to set the present study against the research background of specialized lexicography with particular focus on dictionary usage in ESP and EFL context.

Although Barnhart' study (1962) has been an important landmark in the history of systematic research into dictionary use based on the opinions of the teachers about their students as dictionary users rather than first hand 
report by the users themselves thus making it impossible to yield solid and reliable results.

Later on, Tomaszczyk (1979) conducted a noteworthy investigation involving the dictionary users directly. His study was conducted in Polish and American context and investigated the dictionary needs of non-native learners of English involving the teachers, students, and translators as dictionary users. Questionnaire as a data collection tool was preferred in the study and results gathered thus showed that the bilingual dictionaries were the most preferred ones among the participants.

The first pioneering study in ESP context was conducted by Diab (1990) sought to study the use of dictionary by the nurses in Jordan. He used a protocol method followed by interviews. Findings of the study revealed that the nurses needed help in completing the communicative tasks while existing dictionaries did not cater to their needs. A model of an ESP dictionary for Arab nurses was proposed keeping in view the findings of the study under reference.

Another noteworthy study was conducted by Nielsen (1994) with the eight advanced students of English keeping dictionary use records consisted of ten pages and divided into three columns each. The subjects were assigned the task of translating an English legal text into Danish and completed these records using Danish-English and English-Danish dictionaries. Total number of look ups was 249 including some other sources of information with 55 consultations. The study provided a commentary on five excerpts from those written records and revealed that the available dictionaries did not provide the sufficient information to the participants and information lacks specialized L1 and L2 knowledge in respect of legal language.

Lew (2004) conducted a study with the polish learners of English taking a broad sample of non-English language students as dictionary users. This study was mainly exploratory in nature, conducted to find the patterns that could shed light on the receptive dictionary use by the non-native learners of the English language.

Welker (2010) in her comprehensive study, reviewed 320 dictionaries use based research but absence of research on the use of specialized dictionaries is evidence that this area is still lagging far behind. In Pakistani lexicographic context, a lot of research work has been conducted in general lexicography but no study so far has been ventured on the use of specialized dictionaries by the learners in Pakistan. Therefore, the present study, so far, is going to be the pioneering study in this part of the world.

\section{Objectives of the Study}

The main objective of the study was to profile the language needs of the law graduates and to observe the overall state of dictionary use including gauging the reference skills of the learners.

\section{Research Methodology}

Cohen et al. (2007) claim that there exist two broader research paradigms: naturalistic and positivistic. Lew (2011) mentions a broader distinction between the two broader methodological paradigms namely naturalistic and positivistic ones. Lew (2015) claims that dictionary use research is such an area where both positivistic and naturalistic paradigms can potentially be used in complementary fashion as deemed fit for purpose because dictionary use is a complex activity where some aspects are more quantifiable and controllable while others are qualitative and holistic ones. While Morgan (2007) argues pragmatism that emphasizes the creation of "common concepts and common meanings and joint actions" (p. 67) and the underlying belief in complementarity, namely qualitative and quantitative approaches that can be combined to complement the advantages and disadvantages present in each. Biesta (2010) views pragmatism the hierarchies exist between the constructivist and positivist ways of knowing in order to see what is meaningful for both.

Since the present study is descriptive qualitative research, it is placed within pragmatism following both qualitative and quantitative approaches to the investigation with particular reliance on questionnaire, semi-structured protocols and participant observation to ascertain the interplay between the use of dictionaries and the comprehension of legal language using which preferred lexicographical resources by the law graduates in Pakistan.

As many as six major institutions of higher education in Pakistan, where legal education is being provided, were selected for the study. The respondents were accessed with a view to getting insights on the following:

1) Which dictionaries do the law students prefer to use to solve their language problems?

2) Do these dictionaries cater to the potential language needs of the law students?

3) Do the learners have the sufficient reference skills to use the dictionary efficiently?

To answer the above cited questions, the researcher selected the best methods available in lexicography, to 
investigate empirically the above-mentioned areas.

\subsection{Research Tools}

Data triangulation process was employed to make the research findings more reliable and authentic by using more than one research tools.

\subsubsection{Questionnaire}

A questionnaire consisting of three sections; a) respondent's profile, b) dictionary preference and c) reference skills was developed after many pilot studies for collecting data from the law students.

\subsubsection{Semi Structured Protocol}

To ascertain the actual dictionary's use by the law students in communicative use situation and to verify the responses collected through questionnaire, a written semi protocol study was conducted.

\subsubsection{Participant Observation}

Participant observation was used as a supporting tool to observe the whole process of dictionary consultation. The process was filmed with the help of an assistant and diary notes were also completed by the researcher during the process. These research tools were developed taking insights from the previous valuable lexicographic researches on dictionary use like Iqbal (1987), Hartman (1983) and Diab (1990).

\subsection{Participants}

The population comprised of six hundred law students pursuing law studies in public sector university law colleges in Pakistan. All participants of this study are non-native speakers of the English language pursuing Law studies.

\subsection{Data Collection}

Following pragmatism, a two-phase study was planned. Data was collected using data triangulation techniques, questionnaire for six hundred law students pursuing law studies at major public sector university law colleges in Phase I, observation and semi structure protocol involving twenty volunteer students studying at Bahauddin Zakariya University Gilai Law College, in phase II.

Phase I: A sample of 600 law graduates was selected using non-probability techniques and questionnaires were distributed personally and analysed using SPSS.

\section{Phase II}

As the main objective of the study was to ascertain the interplay between the dictionary use, comprehension of legal language and the usefulness of existing law dictionaries as reported to be used by the law graduates through a questionnaire in phase 1, a semi structured protocol study was designed to observe the learners while engaged in actual dictionary consultation and confirm the responses gathered through the questionnaire in phase one of the study.

\section{Protocol Study}

Twenty participants volunteered to participate in protocol study which was conducted at the Gilani Law College Bahauddin Zakariya University, Multan. The protocol study was delimited to one law college in Multan taking into account the convenience of the researcher in gaining access to the participants and facilities required to conduct the study, finances and other resources. All participants' proficiency level in the English language was good as they had A+ and A grades in the English language tested in previous examination.

The activity took place on campus to avoid external pressure on the students. The researcher introduced the study and its procedure to the participants and comprehensive instructions were provided regarding the completion of tasks. The participants were encouraged to ask questions during the process. Consent forms were duly signed by the participants before the process of protocol study was started.

The participants were provided with dictionaries namely Black's Law dictionary (BLD), Oxford dictionary of Law (ODL), Law Dictionary by Tanzeel ur Rehman (LDTR), Ilmi dictionary of Law (IDL), Chamber's dictionary (CD), and they were also encouraged to use dictionary of their own choice in terms of language and medium including mobile phone dictionaries while searching for information about the selected words. They were also provided written sheets consisting of ten pages. In the first phase of the study, three short legal texts were selected after consulting the relevant teachers. The participants were directed to read the texts one by one and underline words difficult or new to them. In the second phase of protocol study, a list was prepared consisting of those words underlined by the participants. 10 random words were selected out of the whole list 
and the participants were asked to write the selected words on written sheets (already prepared for the purpose and distributed to the students). The participants were asked to write one word on each page and find out the maximum information about the word. They were also advised to note down the process of search including what dictionary they made use of or what information did they search about the word. Whether the search was successful or not? Whether the source was useful or not? And in case it was not, did they consult any alternative source? They were advised to mention the alternative source as well.

\section{Data Analysis}

The data collected from different tools was processed for analysis. Following is the detail of data analysis.

\subsection{Analysis of Questionnaire}

The data analysis of the questionnaires comprised of two stages:

i) The researcher started with exploratory data analysis (EDA). To get a clear insight of the data, it was tabulated in one way, two way and multi way.

ii) The second stage was graphical exploratory data analysis.

Analysis of data collected through questionnaire revealed that all respondents were from diverse linguistic background while learning English as Foreign language. Thus, majority of them $71 \%$ had a mixed method i.e., English-Urdu, 18\% Urdu and 11\% English language as a medium of instruction for teaching Law although by policy medium of instruction was English. The participants reported to use law dictionary more frequently as compared to their previous studies because of the complex nature of the legal English but they have lack of awareness regarding the choice of appropriate dictionary, what a dictionary contains to offer and how to exploit the dictionaries to get the maximum benefit of them. Upon a closer look at the preferential ranking, bilingual dictionary was found to be the most popular which is predictable, as most of the learners usually prefer bilingual dictionary even among other fields, law students are no exception. It was revealed that BLD, ODL, LDTR, CD and IDL along with the online resources (Google being the most popular one) were the most preferred lexicographical resources they used to solve their language problems.

The data indicated that meaning and translation were the most frequently sought information from the law dictionaries as $90 \%$ of the respondents reported to look up meanings.

\subsection{Analysis of Semi Structured Protocols}

The data was analyzed using SPSS and was later tabulated and presented in tables, graphs and percentages which facilitates to have an overview of the entire results. The percentage is calculated out of the whole look ups (i.e.. 535) of ten words by twenty participants. Here is the detailed statistical analysis of the data obtained by protocol study followed by qualitative discussion.

Table 1. The information sought from the dictionaries

\begin{tabular}{lll}
\hline Word Options & Looks Up & Percent \\
\hline Meaning & 200 & 37.4 \\
Synonyms & 11 & 2.1 \\
Etymology & 14 & 2.6 \\
Word Class & 105 & 19.6 \\
Pronunciation & 66 & 12.3 \\
Example of Use & 39 & 7.3 \\
Translation & 95 & 17.8 \\
Any Other & 5 & 0.9 \\
\hline Total & 535 & 100.0 \\
\hline
\end{tabular}

First part of the diary consisted of the type of information that the law students looked up from the dictionaries of their choice. The participants sought eight type of information including meanings, synonyms, etymology, word class, and pronunciation, example of use, translation and other. The above table shows that a majority of the respondents used dictionaries to find out the meanings. The respondents consulted dictionaries for meanings and $37.4 \%(n=200)$ look ups were recorded for meanings. 19.6\% $(n=105)$ consulted dictionary for the information of which word class the specific word belonged to, $17.8 \%(\mathrm{n}=95)$ for translation, $12.3 \%(\mathrm{n}=66)$ for pronunciation, $7.3 \%(\mathrm{n}=39)$ for example of use, $2.6 \%(\mathrm{n}=14)$ for etymology, $2.1 \%(\mathrm{n}=11)$ for synonyms, $0.9 \%$ $(\mathrm{n}=5)$ sought 'any other' information about the selected word. 
The results show that meaning is ranked as the most frequently searched lexical information. Legal language is very complex and the learners need to understand its meanings not only in the English language but in their mother tongue as well to understand it. The following bar graph provides a quick view of the results.

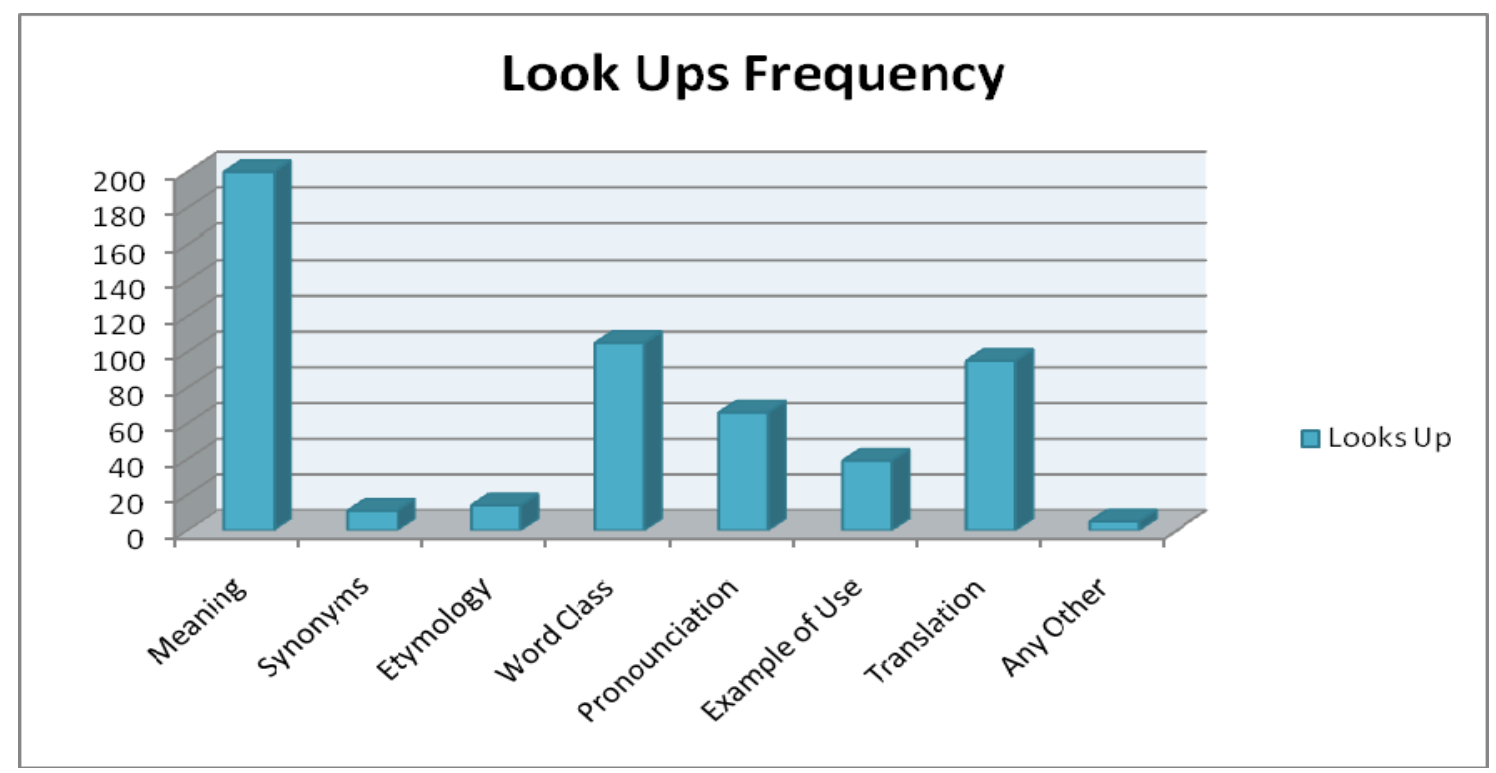

Figure 1. Kind of information law students looked up from law dictionaries

As is apparent from the bar graph, that most frequently sought information by the students is meanings. This same tendency was transpired through the results of the questionnaire in phase one. Therefore, it was also confirmed that law students are more concerned about the meanings as compared to the other syntactic, stylistic or phonological information although a good number of look ups were made for the pronunciation as well.

Table 2. Familiarity of the word

\begin{tabular}{llll}
\hline Response & Frequency & Percentage & Cum. Percentage \\
\hline Yes & 25 & 12.5 & 12.5 \\
No & 175 & 87.5 & 100 \\
Total & 200 & 100 & \\
\hline
\end{tabular}

The participants of the study were asked whether they knew the word already or not. In response, $87.5 \%$ responses were collected in the category of 'No' and $12.5 \%$ in the category of 'Yes'. A highest ratio of the responses fell in the category of 'No' which shows that the selected words were new or unknown to majority of the participants.

Table 3. Medium of dictionary under consultation

\begin{tabular}{llll}
\hline Type of Dictionary & Frequency & Percentage & Cum. Percentage \\
\hline Paper & 83 & 41.5 & 41.5 \\
Digitla & 29 & 14.5 & 56.0 \\
Both & 87 & 43.5 & 99.5 \\
Any Other & 1 & 0.5 & 100 \\
Total & 200 & 100 & \\
\hline
\end{tabular}

The learners were asked to record on the diary about the medium of dictionary they exploited for the information. The results showed that majority of the word $43.5 \%$, the respondents reported to use both paper and digital dictionary. The second highest ratio of the words $41.5 \%$ were searched from the paper dictionary, $14.5 \%$ digital and for a very few words, 'some other' resource was used. 
The results indicated that the law students consulted both type of resources to find the information about the selected words. Field notes and video tapes were minutely observed to match the findings of students' written record sheets. It was observed that students consulted paper dictionaries and soon resorted to digital resources including mobile dictionaries in case they failed to find the required information but some of the students preferred to use only paper dictionary. Results are presented in the following table:

Table 4. Name of dictionaries and resources consulted

\begin{tabular}{llll}
\hline Name of Dictionary & Frequency & Percentage & Cum. Percentage \\
\hline Online/Google & 9 & 4.5 & 4.5 \\
BLD (soft, paper) & 61 & 30.5 & 35.0 \\
ODL (soft, paper) & 35 & 17.5 & 52.5 \\
RLD & 35 & 17.5 & 70 \\
CD & 2 & 1 & 71 \\
BLgL & 2 & 1 & 72 \\
TRLD & 16 & 8 & 80 \\
IDL & 16 & 8 & 88 \\
Merriam Webster & 4 & 2 & 90 \\
Mobile App/Dictionary & 19 & 9.5 & 99.5 \\
Fire Fox & 1 & 0.5 & 100 \\
Total & 200 & 100 & \\
\hline
\end{tabular}

The table above shows the written record the students kept of the consulted lexicographical resources during the protocol study that revealed that the amongst the most frequently consulted dictionary was BLD (soft copy, paper dictionary) used to search for majority of the words $30.5 \%$, while the percentage for consulting ODL was 17.5\%, RLD 17.5, Mobile App/Dictionary 9.5\%, TRLD 8\%, IDL 8\%, Online/Google 4.5\%, Merriam Webster 2\%, CLD $1 \%$, BLgL $1 \%$, Fire fox $0.5 \%$ respectively.

The results of the protocol study are in line with the survey results in which the law students reported to use BLD as the most frequently used dictionary and the second popular dictionary was ODL with a variation in the percentage of TRLD use $8 \%$. On the whole, the percentage of the digital and online resources is $15.5 \%$.

A quick glance can reveal the tendency of the students to consult the types of dictionaries. It is important to mention that the researcher tried to provide the maximum number of paper dictionaries (BLD, ODL, LDTR, ILD, $\mathrm{CD})$ to the participants and students were encouraged to bring their own.

Table 5. Frequency of problems faced while retrieving information

\begin{tabular}{lll}
\hline Response & Frequency & Percentage \\
\hline Yes & 177 & 88.5 \\
No & 23 & 11.5 \\
Total & 200 & 100 \\
\hline
\end{tabular}

The participants of the study were directed to record the problems they encountered during search for information. Majority of the respondents $88.5 \%$ replied in 'YES' while $11.5 \%$ in 'NO'.

The results are evident that the law students were unable to find the required information from only one dictionary and the existing dictionaries were found lacking in providing the satisfactory answers to most of the queries of the law students. Although, majority of them managed to find the information about the words as directed by the researcher and completed the columns but they had to fall back to alternative resources frequently and it took long in searching the information about the selected lexical items which showed the insufficiency of their reference skills. In a follow up interview, the law graduates revealed that formal instruction on dictionary use had never been the part of their scheme of study for which they felt deprived.

Table 6. Opinions regarding the protocol study

\begin{tabular}{lllll}
\hline & Frequency & Percent & Valid Percent & Cumulative Percent \\
\hline No & 1 & 5.0 & 5.0 & 5.0 \\
Yes & 19 & 95.0 & 95.0 & 100.0 \\
Total & 20 & 100.0 & 100.0 & \\
\hline
\end{tabular}


The participants were asked if they found the activity interesting, 95\% $(n=19)$ overwhelmingly replied in 'Yes' and one participant in 'No' which showed that majority of the respondents found the protocol study very useful and interesting.

\subsubsection{Problems encountered and their solution}

In a subsequent question, the participants were asked to record the problems they encountered during the consultation process. They reported to face some problems regarding pronunciation, synonyms, translation of some words, definition and example of use. The written records also revealed that majority of the participants faced problems in finding the suitable meaning, equivalents in Urdu, synonyms and etymology of the words.

They were also asked to record how they solved the problems they encountered. These respondents reported to use online resources amongst which Google and Merriam Webster secured the highest ratio. The participants $88.5 \%$ faced difficulty in retrieving the information successfully from the dictionaries while $11.5 \%$ reported to find out the desired information. Although the problem were somehow managed using alternative mediums and sources but information regarding cultural meanings, satisfactory definitions, example of use, full equivalents and synonyms were missing from these law dictionaries.

\subsection{Participant Observation}

When this result was rechecked and compared using the observation notes and video clips following thematic approach, it was revealed that students used mobile apps more times than they reported. Their frequent practice was to consult the paper dictionary but they were found to resort to online resources quickly and then again to the paper dictionary. The reason may be the easy access to information through technology while the paper dictionary takes time for it but in some cases, after consulting the mobile apps they returned back to the paper dictionary again We can interpret the reason for the tendency in the following ways: i) the students found it easy and time saving strategy to consult the digital resources, ii) the students were provided a good number of paper dictionaries consisting of the most popular ones as transpired in survey results. The only access to digital dictionaries was their mobiles with few students, iii) there was no internet access in the campus. The students with the facility of mobile data were capable of using more online resources while the rest of the law students either relied on offline resources or paper dictionaries. It was reported in the follow up interviews that internet facility was not available to the students within the campus and students relied either on paper dictionaries or mobile data in case they owned mobile phones, offline dictionaries and mobile apps. During the class, they rarely need to use dictionaries because the teachers were responsible to cover the contents using lecture method and provided sufficient information during the class. Further they informed that they used all type of dictionaries mostly at home because they needed assistance for decoding and encoding the legal texts for exams preparation, making assignments or preparing presentations.

\section{Conclusion}

Analysis of the data revealed that majority of the respondents were more inclined toward consulting both types of dictionaries namely specialized law dictionaries and general language dictionaries (in terms of language and medium) along with the online resources as an ideal combination to resolve their language problems. It was also revealed that participant's reference skills were weak. Findings of the semi structured protocols, however, are in line with majority of the key studies in the area of user research like (Tomaszczyk,1979; Diab 1990; Bejoint, 1981) where the highest ratio of the respondents focused on meanings and resorted to dictionaries to find the meanings of difficult or new words or terms and law students are no exception.

They feel more convenient in consulting online resources but they resort to the paper dictionaries because of the teachers' instruction specifically to use the BLD. The law dictionaries were found lacking in potential to cater the needs of the learners specifically in communicative use situation as a higher number of respondents complained about the insufficiency of 'example of use' and 'full equivalents' appropriate to serve the purpose, etymology and appropriate definitions. synonyms were not included in paper dictionaries for which they consulted Google and Merriam Webster. It was also observed that the law students consulted the paper dictionaries at the first place but quickly fall back to the mobile dictionaries without bothering to spend more time in searching the information in case they failed to find the one. Moreover, the law graduates have poor reference skills which need to be addressed on priority basis.

\section{References}

Barnhart, C. L. (1962). Problems in editing commercial monolingual dictionaries. In W. Householder, W. Fred \& S. Saporta (Eds.), Problems in lexicography (pp. 161-181). Bloomington: Indiana University.

Biesta, G. (2010). Pragmatism and the philosophical foundations of mixed methods research. Sage handbook of 
mixed methods in social and behavioral research, 2, 95-118. https://doi.org/10.4135/9781506335193.n4

Cohen, L., Manion, L., \& Morrison, K. (2007). Research methods in education. Routledge.

Diab, T. (1990). Pedagogical lexicography: A case study of Arab nurses as dictionary users. Tubingen: Max Niemeyer Verlag. https://doi.org/10.1515/9783111347783

Diab, T. (Ed.). (2017). Pedagogical lexicography: A case study of Arab nurses as dictionary users (vol. 31). Walter de Gruyter GmbH \& Co KG.

Dziemianko, A., \& Lew, R. (2006). Research into dictionary use by Polish learners of English: Some methodological considerations.

Fuertes-Olivera, P., Bergenholtz, H., Nielsen, S., \& Amo, M. N. (2012). Classification in Lexicography.

Fuertes-Olivera, P. A., \& Tarp, S. (2011). Lexicography for the third millennium: Cognitive-oriented specialiseddictionaries for learners. Ibérica, 21, 141-162.

Hartmann, R. (2000). European Dictionary Culture: the Exeter case study of dictionary use among university students, against the wider context of the reports and recommendations of the Thematic Network Project in the Area of Languages (1996-1999, pp. 385-391). In Proceedings of the Ninth EURALEX International Congress, EURALEX 2000: Stuttgart, Germany, August 8th-12th, 2000.

Householder, F. W., \& Saporta, S. (Eds.) (1967). Problems in Lexicography. Bloomington: Indiana University.

Lew, R. (2004). Which dictionary for whom? receptive use of bilingual, monolingual and semi-bilingual dictionaries by Polish learners of English. Robert Lew.

Lew, R. (2011). User studies: Opportunities and limitations.

Lew, R. (2011a). Studies in Dictionary Use: Recent Developments. International Journal of Lexicography, 24(1), $1-4$.

Lew, R. (2015). Opportunities and limitations of user studies. Research into dictionary use/Wörterbuchbenutzungsforschung. 5. Arbeitsbericht des wissenschaftlichen Netzwerks, Internetlexikografie, 6 .

McCreary, D. R., \& Dolezal, F. (1998). Language learners and dictionary users: Bibliographic findings and commentary. Actes EURALEX, 98, 611-618.

Morgan, D. L. (2007). Paradigms lost and pragmatism regained: Methodological implications of combining qualitative and quantitative methods. Journal of Mixed Methods Research, 1(1), 48-76. https://doi.org/10.1177/2345678906292462

Nielsen, S. (1994). The bilingual LSP dictionary: principles and practice for legal language (vol. 24). Gunter Narr Verlag.

Nielsen, S. (2015). Legal lexicography in theory and practice. Estudios De Lexicografia, 4, 111-120.

Nielsen, S., \& Tarp, S. (2009a). Introduction: Nothing is More Practical than a Good Theory.

Nielsen, S., \& Tarp, S. (2009b). Lexicography in the 21st Century. In Honour of Henning Bergenholtz (ix-xi), Terminology and Lexicography Research and Practice (vol. 12). Amsterdam: John Benjamins.

Nikuze, E. (2014). Towards a theoretically motivated model for the lexicographic representation of Kinyarwanda phrasemes in General Kinyarwanda Dictionaries. Doctoral dissertation, Stellenbosch: Stellenbosch University.

Peters, P., \& Fernández, T. (2013). The lexical needs of ESP students in a professional field. English for Specific Purposes, 32(4), 236-247. https://doi.org/10.1016/j.esp.2013.05.002

Tarp, S. (2009). Reflections on lexicographical user research. Lexikos, 19(1). https://doi.org/10.4314/lex.v19i1.49131

Tarp, S. (2012). Specialised lexicography: 20 years in slow motion. Ibérica, 24, 117-128.

Tomaszczyk, J. (1979). Dictionaries: users and uses. Glottodidactica, 12(10), 3-11.

\section{Copyrights}

Copyright for this article is retained by the author(s), with first publication rights granted to the journal.

This is an open-access article distributed under the terms and conditions of the Creative Commons Attribution license (http://creativecommons.org/licenses/by/4.0/). 